\title{
Training On The Utilization Of Desktop Mendeley As A Reference Tool In Writing Scientific Papers For Teachers Of SMP Swasta Gita Surya Eban
}

\author{
Justin Eduardo Simarmata ${ }^{1 *}$, Ni Putu Yuni Astriani Dewi ${ }^{2}$, Vinsensia Ulia Rita Sila ${ }^{2}$, Yunawati Sele \\ 2, Muhammad Amran Shidik ${ }^{2}$, \\ ${ }^{1}$ Mathematics Education Study Program, Faculty of Education, University of Timor, Kefamenanu, \\ Indonesia \\ ${ }^{2}$ Biology Education Study Program, Faculty of Education, University of Timor, Kefamenanu, \\ Indonesia \\ *Email: justinesimarmata@unimor.ac.id
}

\begin{abstract}
One of the software for compiling a bibliography automatically can take advantage of the facilities of the Mendeley Desktop application. Mendeley Desktop is a reference management software that helps organize scientific articles, namely in creating citations and bibliography. With this software, writers can manage reading sources that are used as references in compiling their writings. The use of Mendeley Desktop can also be integrated with Microsoft Word, so it can be more easily for writers for each scientific paper. The purpose of holding this training activity is to help the teachers of SMP Swasta Gita Surya Eban in order to utilize of the facilities provided by the software and the citations and references on the Mendeley Desktop so that scientific writing can be done more easily, quickly, and efficiently. From the training results, it was found that the training carried out could add knowledge and solutions to the use of Mendeley Desktop with the evaluation results increase significantly. The writers hope that by holding this training, teachers at SMP Swasta Gita Surya Eban can apply the citation / reference software from Mendeley Desktop in writing scientific papers.
\end{abstract}

Keywords: Mendeley Desktop Training, Citation, Reference Manager

\begin{abstract}
Abstrak
Salah satu perangkat lunak untuk penyusunan daftar pustaka secara otomatis dapat memanfaatkan fasilitas dari aplikasi Mendeley Desktop. Mendeley Desktop adalah software manajemen referensi yang membantu mengorganisir artikel ilmiah yaitu dalam membuat kutipan dan daftar pustaka. Dengan perangkat lunak ini, penulis dapat mengelola sumber-sumber bacaan yang digunakan sebagai referensi atau acuan dalam menyusun tulisannya. Penggunaan Mendeley Desktop juga dapat terintegrasi dengan Microsoft Word sehingga sangat memudahkan bagi penulis untuk setiap karya ilmiahnya. Tujuan diadakan kegiatan pelatihan ini adalah untuk membantu Guru-Guru SMP Swasta Gita Surya Eban agar dapat memanfaatkan fasilitas yang disediakan oleh perangkat lunak secara maksimal dan sitasi serta referensi pada Mendeley Desktop sehingga penulisan karya ilmiah dapat dilakukan dengan lebih mudah, cepat dan efisien. Dari hasil pelatihan diperoleh bahwa pelatihan yang dilaksanakan dapat menambah pengetahuan dan solusi terhadap pemanfaatan Mendeley Desktop dengan hasil evaluasi yang meningkat secara signifikan. Penulis berharap dengan diadakannya pelatihan ini, Guru-Guru di SMP Swasta Gita Surya Eban dapat memanfaatkan perangkat lunak sitasi/ referensi dari Mendeley Desktop dalam menulis karya ilmiah
\end{abstract}

Kata Kunci: Pelatihan Mendeley Desktop, Sitasi, Reference Manager

\section{PENDAHULUAN}

PP Tahun 2005 tentang standar nasional pendidikan menuntut reformasi guru untuk memiliki tingkat kompetensi yang lebih tinggi, baik kompetensi pedagogik, kepribadian, profesional maupun 
Justin, et al Training on the utilization of desktop mendeley as a reference tool in writing scientific papers for teachers of SMP Swasta Gita Surya Eban

sosial. Khusunya dalam peningkatan kompetensi guru dengan menggunakan prinsip-prinsip ilmiah, relevan, sistematik, konsisten, aktual, kontekstual dan fleksibel dan sebagainya diperlukan dalam penilaian kinerja guru. Hal ini sejalan dengan kebijakan pengembangan profesi guru secara berkelanjutan, antara lain yaitu pengembangan profesi guru dalam karya tulis ilmiah melalui publikasi ilmiah (Pangestika, 2015).

Menurut (Elin, 2019) perkembangan teknologi informasi dalam dunia pendidikan sudah semakin meningkat, sehingga guru-guru harus mengenal berbagai aplikasi yang disediakan oleh para penyedia jasa informasi seperti database jurnal online dan offline, yang berisi kumpulan artikel dari berbagai jurnal ilmiah. Banyak peneliti yang menganggap bahwa penggunaan jurnal online sangat membantu dan memudahkan dalam mendukung kegiatan penelitian dan pengkajian, baik untuk menyusun proposal penelitian, pembuatan artikel ilmiah ataupun melakukan pembahasan dalam menyelesaikan karya ilmiah. Namun apabila artikel jurnal online yang sudah diunduh tidak didokumentasikan dengan benar, maka akan sangat menyulitkan ditemukan kembali, apabila sewaktu-waktu diperlukan dalam pembuatan referensi manager (Windarto, 2018).

Artikel jurnal online tersebut sebenarnya akan mudah ditemukan kembali, apabila dikelola dengan baik dalam bentuk database. Namun karena kesibukan dan ketersediaan waktu sangat terbatas mengakibatkan database referensi manager tidak pernah selesai dibangun dan dipelihara. Akibatnya seringkali artikel tersebut tercecer di berbagai tempat. Salah satu aplikasi database yang dapat digunakan untuk mengelola artikel jurnal online adalah mendeley desktop (Kosasi, 2019). Sebenarnya ada beberapa perangkat lunak yang tersedia, sifatnya free dan dapat digunakan untuk mengelola reference manager. Namun aplikasi tersebut seringkali menyebabkan guru-guru menjadi kesulitan untuk menentukan pilihan yang akan digunakan dalam penyelesaian karya ilmiah (Windarto, 2018). Ada hal penting yang harus menjadi pertimbangan dalam memilih aplikasi, yaitu sejauh mana sebuah aplikasi dapat meringankan tugas pustakawan (Iswanto, 2019). Yang dimaksudkan dengan meringankan pekerjaan adalah memudahkan, mempercepat dan kompatibel dengan aplikasi lain yang sudah digunakan.

Untuk membantu penulisan sitasi dengan daftar pustaka yang terintegrasi dengan software pengolah kata seperti microsoft word, maka pengelolaan sitasi yang terintegrasi dapat dilakukan dengan menggunakan tools atau menu perangkat lunak tersebut (Setiawan, 2019). Dalam pengorganisiran penelitian maka kita dapat memanfaatkan beberapa perangkat lunak, serta bergabung dengan penulis lain secara online agar karya atau tulisan yang dipublikasi bersumber dari penelitian terakhir. File referensi dapat diberi keterangan agar mempermudah dalam pencarian, biasanya dalam format PDF. Dari uraian di atas, penulis berkeinginan untuk memberikan pelatihan penggunaan aplikasi mendeley desktop dalam mendukung penulisan para peneliti khususnya guru. Banyaknya guru belajar menggunakan mendeley desktop secara otodidak sehingga fasilitas pada mendeley belum termanfaatkan secara maksimal, terutama dalam pembuatan rerefensi secara otomatis untuk mendukung dalam setiap karya tulis guru itu sendiri. Solusi yang ditawarkan adalah pelatihan pemanfaatan fasilitas seperti membuat daftar referensi secara otomatis pada perangkat lunak mendeley desktop.

mendeley desktop adalah software manajemen referensi yang membantu mengorganisir artikel ilmiah yaitu dalam membuat kutipan dan daftar pustaka, selain itu pengguna software ini juga dapat berkolaborasi dalam jaringan sosial (Rahmawati, 2018). Dalam software ini kita dapat membuat data base referensi baik secara manual maupun secara online (Hutajulu, 2020). Manfaat dari software mendeley desktop menurut Trisasti dalam (Rahmawati, 2018) adalah :

a. Membantu mengorganisir penelitian;

b. Dapat berkolaborasi dengan peneliti lain secara online;

c. Dapat menemukan publikasi penelitian terakhir;

d. Sebagai database referensi, file referensi seperti buku atau artikel dari jurnal dalam bentuk PDF bisa disimpan dan diberi keterangan yang tepat untuk membantu mempermudah pencarian; 
Justin, et al Training on the utilization of desktop mendeley as a reference tool in writing scientific papers for teachers of SMP Swasta Gita Surya Eban

e. File-file PDF yang disimpan juga bisa dibuka, dibaca, dan diberi catatan- catatan dengan sticky notes atau highlight;

f. Tulisan yang dibuat dengan Ms. Word, Open Office atau LaTex bisa dihubungkan dengan software mendeley desktop sehingga sitasi dan daftar referensi (bibliography) bisa disusun secara otomatis;

g. Mendeley Desktop juga bisa dihubungkan dengan software manajemen referensi lainnya seperti EndNote, Papers dan Zotero;

h. Bisa diakses dari manapun via internet di laptop atau dengan aplikasi mendeley untuk iPhone dan iPad.

i. Selain itu melalui jaringan internet, bisa ditemukan peneliti atau kelompok peneliti/penulis lain yang memiliki kesamaan minat atau melakukan pencarian artikelartikel yang sehubungan dengan topik penelitian yang sedang dikerjakan

SMP Sawasta Gita Surya Eban adalah Sekolah Menengah Pertama (SMP) Swasta yang berlokasi di Jln. Hatta No.07, Eban, Kec. Miomafo Barat, Kab. Timor Tengah Utara, Provinsi Nusa Tenggara Timur. Sesuai dengan latar belakang tim pengabdian masyarakat maka yang menjadi sasaran dari pengabdian masyarakat ini adalah para guru SMP Swasta Gita Surya Eban. Khususnya guru-guru yang akan mengurus kenaikan pangkat yang dimana persyaratannya harus memiliki karya ilmiah yang diterbitkan di jurnal sesuai bidang guru yang bersangkutan. Tujuan diadakan kegiatan pelatihan ini adalah untuk membantu Guru-Guru SMP Swasta Gita Surya Eban agar dapat memanfaatkan fasilitas yang disediakan oleh perangkat lunak secara maksimal dan sitasi serta referensi pada mendeley desktop sehingga penulisan karya ilmiah dapat dilakukan dengan lebih mudah, cepat dan efisien. Pengetahuan guru-guru SMP Swasta Gita Surya Eban tentang sitasi penelitian atau karya ilmiah masih sebatas manual. Dalam membuat sitasi perlu diperhatikan prosedurnya misal nama jurnal yang harus disingkat atau ditulis penuh. Jika disingkat, bagaimana menyingkatnya serta bagaimana penyusunan daftar pustakanya. Penyusunan daftar pustaka ada yang menggunakan penomoran dan ada yang menggunakan alfabetis. Oleh kerena itu perlu disarankan menggunakan perangkat lunak seperti mendeley desktop. Sedangkan masih banyak guru-guru yang belum mengetahui cara sitasi menggunakan perangkat lunak tersebut, sehingga menyebabkan guruguru melakukan kesalahan dalam mensitasi dan membuat daftar pustaka. Oleh karena itu, berdasarkan analisis situasi tersebut, tim Pengabdian Kepada Masyarakat Program Studi S1 Pendidikan Matematika dan Pendidikan Biologi, FIP, Unimor melaksanakan kegiatan pengabdian Pelatihan Pemanfaatan Mendeley Desktop Sebagai Reference Tool dalam Penulisan Karya Tulis Ilmiah Bagi Guru-Guru SMP Swasta Gita Surya Eban.

\section{METODE PELAKSANAAN}

Metode pelaksanaan dalam kegiatan pengabdian ini dapat penulis uraikan sebagai berikut:

1. Persiapan

Tim pengabdian mempersiapkan perizinan dan undangan, tempat dan konsumsi serta materi pelatihan yang dibutuhkan termasuk contoh secukupnya untuk praktik agar kegiatan pelatihan berjalan secara optimal.

2. Pelatihan Mendeley Desktop

Pada bagian ini, peserta diajarkan bagaimana menginstall mendeley, set plugin ke Microsoft Word, menggunakan mendeley desktop, mengutip dan mengedit kutipan hingga menjadi referensi pada artikel dari kutipan yang diambil.

3. Evaluasi

Teknik evaluasi hasil kegiatan adalah dengan mengadakan pre-test dan post-test kepada peserta pelatihan tentang pengetahuan awal dan pengetahuan setelah mendapatkan pelatihan. 
Justin, et al Training on the utilization of desktop mendeley as a reference tool in writing scientific papers for teachers of SMP Swasta Gita Surya Eban

\section{HASIL DAN PEMBAHASAN}

Sesi pelatihan pemanfaatan mendeley desktop dimulai terlebih dahulu dengan mengenalkan pada peserta mengenai software mendeley desktop. Mendeley desktop merupakan istilah yang digunakan sebagai software atau freeware yang menyediakan program reference manager. Program tersebut akan memudahkan penulis dalam mencantumkan referensi. Ada berbagai macam software yang dapat dipilih untuk mempermudah menuliskan referensi, salah satunya mendeley desktop.

Teknik yang digunakan dalam menyampaikan materi pelatihan adalah workshop dengan menggunakan alat bantu multimedia berupa laptop, LCD, alat peraga, pre-test dan post-test. Berikut ini dokumentasi pelaksanaan kegiatan pelatihan.

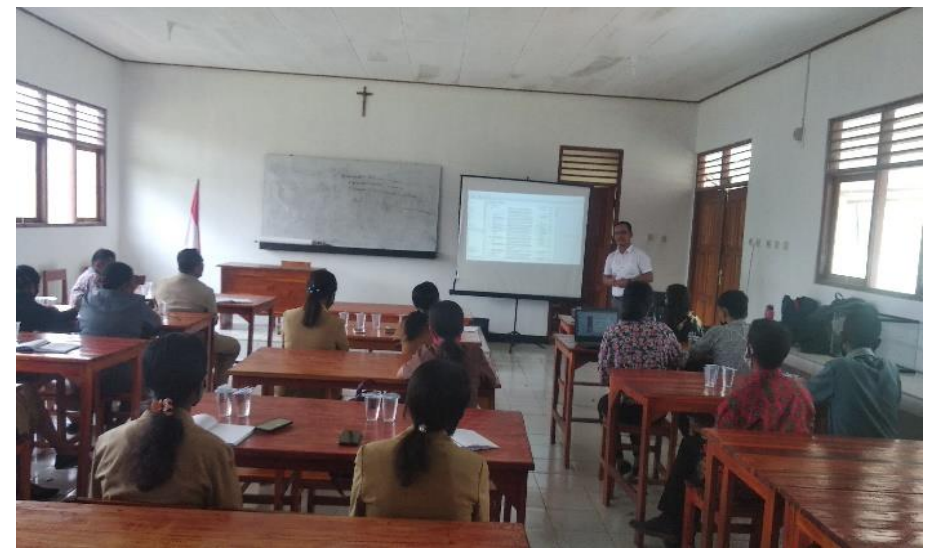

Gambar 3.1. Pemaparan Materi Pemanfaatan Mendeley Desktop

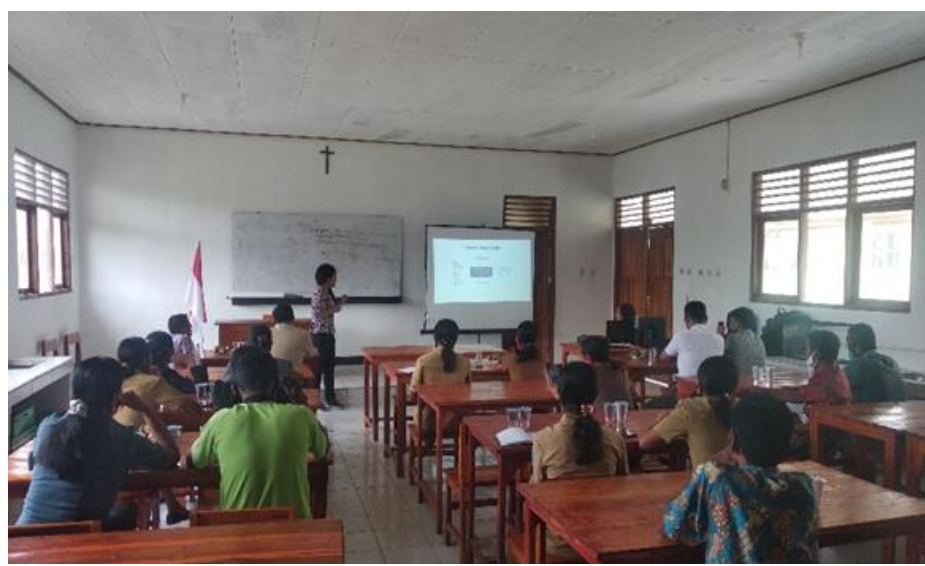

Gambar 3.2. Praktek Pemanfaatan Mendeley Desktop 


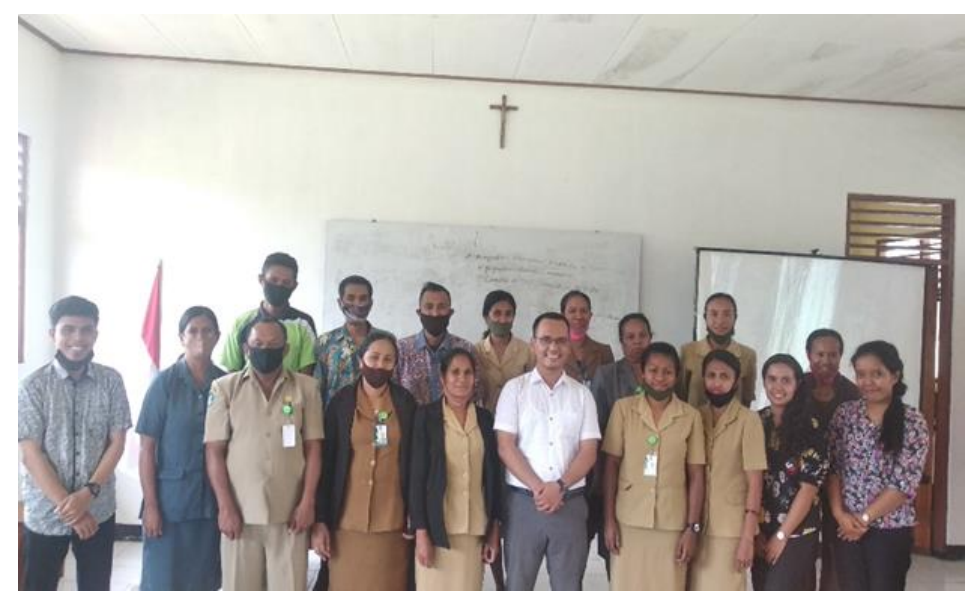

Gambar 3.3. Foto Bersama dengan Guru SMP Swasta Gita Surya Eban

Kegiatan pelatihan pemanfaatan mendeley desktop ini telah dilaksanakan pada tanggal 17 s/d 18 November 2020, dengan perincian jadwal dan materi sebagai berikut.

\begin{tabular}{|r|c|l|c|}
\hline Tanggal & Waktu & Materi & Penyaji \\
\hline 17 Nov 2020 & $09.00-12.00$ WITA & Pengenalan Mendeley Desktop & TIM \\
\hline 18 Nov 2020 & $09.00-12.00$ WITA & Penggunaan Mendeley Desktop (tutorial) & TIM \\
\hline
\end{tabular}

Tabel 3.1. Jadwal Kegiatan Pelatihan

Hasil Evaluasi terhadap kegiatan pelatihan ini dapat dilihat pada tabel di bawah ini.

\begin{tabular}{|c|c|c|c|c|c|c|c|}
\hline No & Komponen & \multicolumn{6}{|c|}{ Hasil Tes } \\
\hline \multirow{12}{*}{1} & \multirow{12}{*}{$\begin{array}{l}\text { Pelatihan Pemanfaatan } \\
\text { mendeley desktop dalam } \\
\text { membuat citasi karya ilmiah }\end{array}$} & \multicolumn{3}{|c|}{ Pre-Test } & \multicolumn{3}{|c|}{ Post-Test } \\
\hline & & \multicolumn{2}{|c|}{ Jumlah } & $\%$ & \multicolumn{2}{|c|}{ Jumlah } & $\%$ \\
\hline & & Benar 10 & 0 & 0 & Benar 10 & 2 & 11.11 \\
\hline & & Benar 9 & 0 & 0 & Benar 9 & 4 & 22.22 \\
\hline & & Benar 8 & 4 & 22.22 & Benar 8 & 3 & 16.67 \\
\hline & & Benar 7 & 2 & 11.11 & Benar 7 & 5 & 27.78 \\
\hline & & Benar 6 & 7 & 38.89 & Benar 6 & 3 & 16.67 \\
\hline & & Benar 5 & 3 & 16.67 & Benar 5 & 1 & 5.55 \\
\hline & & Benar 4 & 2 & 11.11 & Benar 4 & 0 & 0 \\
\hline & & Benar 3 & 0 & 0 & Benar 3 & 0 & 0 \\
\hline & & Benar 2 & 0 & 0 & Benar 2 & 0 & 0 \\
\hline & & Benar 1 & 0 & 0 & Benar 1 & 0 & 0 \\
\hline
\end{tabular}

Tabel 3.2. Hasil Tes

Berdasarkan hasil tes di atas, dapat diketahui kemajuan pengetahuan peserta tes menyangkut materi yang telah disampaikan. Pada sesi pre-test, peserta tes maksimal dapat menjawab 8 soal dengan benar sebanyak $22,22 \%$ sementara pada sesi post-test, peserta mampu menjawab semua soal dengan benar sebanyak 10 soal sebesar $11,11 \%$.

Hal ini meunjukkan bahwa yang peserta ketahui dalam membuat referensi karya ilmiah masih kurang memadai sebelum dilaksanakan pelatihan. Setelah pelaksanaan pelatihan tersebut, ada peningkatan pengetahuan peserta secara signifikan. Terlihat bahwa rata-rata peserta telah memperolah tambahan pengetahuan yang cukup memadai perihal apa yang telah dipaparkan tim pengabdian, bahwa pada 
Justin, et al Training on the utilization of desktop mendeley as a reference tool in writing scientific papers for teachers of SMP Swasta Gita Surya Eban

umumnya peserta telah mampu menjawab seluruh soal yang diberikan dan referensi membuat sitasi karya ilmiah semakin baik.

Secara keseluruhan terlihat pelatihan ini memberi dampak positif bagi peserta dimana $100 \%$ peserta menyatakan akan menggunakan aplikasi ini dalam publikasi ilmiah mereka. Keseluruhan peserta sudah cukup mampu membuat kutipan dan daftar pustaka dengan pemanfaatan software mendeley desktop dengan baik dan benar.

\section{KESIMPULAN}

Berdasarkan hasil pelaksanaan Pengabdian Kepada Masyarakat yang telah dilakukan, dapat ditarik beberapa simpulan sebagai berikut;

1. Pengetahuan Guru-Guru SMP Swasta Gita Surya Eban tentang penggunaan mendeley desktop secara umum telah meningkat setelah dilaksanakan pelatihan. Hal ini ditunjukkan dari hasil post-test dan para guru telah mampu memanfaatkan fasilitas yang disediakan oleh perangkat lunak secara maksimal.

2. Penyampaian pelatihan pemanfaatan mendeley desktop kepada peserta pelatihan dapat meningkatkan pengetahuan sekaligus sebagai stimulant agar Guru-Guru SMP Swasta Gita Surya lebih kreatif membuat sitasi serta referensi pada mendeley desktop sehingga penulisan karya ilmiah dapat dilakukan dengan lebih mudah, cepat dan efisien.

\section{UCAPAN TERIMAKASIH}

Ucapan terima kasih disampaikan kepada Rektor Universitas Timor Kefamenanu yang telah mengizinkan kami turut berpartisipasi dalam kegiatan pengabdian kepada masyarakat. Ucapan yang sama kami tujukan kepada Dekan Fakultas Ilmu Pendidikan dan Ketua Program Studi Pendidikan Matematika Universitas Timor, Kefamenanu, Nusa Tenggara Timur.

Terima kasih juga kami sampaikan kepada Ketua UPT LPPM Universitas Timor Kefamenanu beserta staff nya yang selalu membantu kami dalam sisi administratif. Selanjutnya kami juga mengucapkan terima kasih kepada Kepala Sekolah dan Guru - Guru SMP Swasta Gita Surya Eban, Nusa Tenggara Timur, karena atas bantuannya pengabdian kepada masyarakat ini dapat dilaksanakan dengan baik dan lancar.

\section{DAFTAR PUSTAKA}

Elin, L. H., Simarmata, J. E., Siahaan, M. M. L., Mone, F., Delvion, E. B. S., Laja, Y. P. W., ... \& Dewi, N. P. Y. A. (2019). Fast training right on the national examination question for junior high school. ABDIMAS TALENTA: Jurnal Pengabdian Kepada Masyarakat, 4(2), 125-128.

Iswanto, R., Wince, I., \& Marleni, M. (2019). Optimalisasi Pemanfaatan Aplikasi SLiMS dalam Meningkatkan Kinerja Pustakawan pada Perpustakaan InstitutAgama Islam Negeri Curup. Jurnal Ilmu Perpustakaan dan Informasi, 3(2).

Hutajulu, M., Senjayawati, E., \& Minarti, E. D. (2020). Pendampingan Dan Penulisan Karya Ilmiah Berbantuan Mendeley Bagi Guru Sekolah Menengah Di Kecamatan Pangalengan. Abdimas Siliwangi, 3(1), 48-59.

Kosasi, S. (2019, December). Pemanfaatan Aplikasi Mendeley desktop Mengelola Referensi Publikasi Karya Ilmiah Mahasiswa. In SNPMas: Seminar Nasional Pengabdian pada Masyarakat (pp. 64-74).

Pangestika, R. R., \& Alfarisa, F. (2015). Pendidikan profesi guru (PPG): Strategi pengembangan profesionalitas guru dan peningkatan mutu pendidikan Indonesia. In Makalah Prosiding Seminar Nasional (Vol. 9). 
Justin, et al Training on the utilization of desktop mendeley as a reference tool in writing scientific papers for teachers of SMP Swasta Gita Surya Eban

Rahmawati, C., Meliyana, M., Yuliana, Y., \& Zain, H. (2018). Pelatihan Software Mendeley Dalam Peningkatan Kualitas Artikel Ilmiah Bagi Dosen. Jurnal Pengabdian Kepada Masyarakat, 8(1), 30-36.

Setiawan, D., Hamzah, H., \& Arlenny, A. (2019). Pelatihan Ms. Word \& Mendeley Untuk Penulisan Karya Ilmiah Dosen Fakultas Teknik Unilak. Lembaga Penelitian dan Pengabdian Kepada Masyarakat, 3(1), 172-179.

Windarto, A. P., Hartama, D., Wanto, A., \& Parlina, I. (2018). Pelatihan Pemanfaatan Mendeley Desktop Sebagai Program Istimewa Untuk Akademisi Dalam Membuat Citasi Karya Ilmiah. AKSIOLOGIYA: Jurnal Pengabdian Kepada Masyarakat, 2(2), 145-150. 